\title{
Regal Electrochemistry: Sensing of the Synthetic Cathinone Class of New Psychoactive Substances (NPSs)
}

Fang Tan, Jamie P. Smith, Oliver B. Sutcliffe and Craig E. Banks*

Faculty of Science and Engineering, School of Science and the Environment, Division of Chemistry and Environmental Science, Manchester Metropolitan University, Chester Street, Manchester M1 5GD, UK

Communication to: Analytical Methods

*To whom correspondence should be addressed.

Email: c.banks@mmu.ac.uk; Tel: $\quad+44 \quad$ (0)161-247-1196; Fax: $\quad+44 \quad$ (0)161-247-6831; Website: www.craigbanksresearch.com 


\begin{abstract}
In this paper the concept of 'Regal Electrochemistry' is expanded towards the electrochemical sensing of Novel Psychoactive Substances (NPSs) namely synthetic cathinone derivatives where British coinage is used as the electrochemical sensor. In this proof-ofconcept approach, the electrochemical sensing of mephedrone (4-MMC) and 4'-methyl- $N$ ethylcathinone (4-MEC) is shown to be possible using a British 1 pence coin for the first time. This novel electrochemical protocol is validated towards the detection of cathinone derivatives in a seized street sample that has been independently analysed via high performance liquid chromatography demonstrating its potential use as a novel electrochemical sensor for NPSs.
\end{abstract}

Keywords: New Psychoactive Substances; Legal highs; Electrochemistry; Regal Electrochemistry; $1 \mathrm{p}$ sensor 


\section{Introduction}

Synthetic cathinones are a class of New Psychoactive Substance (NPS; substances not controlled substances by national drug legislation) that are derived from cathinone, an organic stimulant found in Khat (Catha edulis) and are both similar in structure and pharmacological effect as the phenethylamine class of psychoactives (e.g. amphetamine and methamphetamine). ${ }^{1,2}$ Despite being controlled by drug legislation internationally (e.g. Misuse of Drugs Act 1971) synthetic cathinone-derivatives are still prevalent in many NPS products marketed as 'legal highs'-5 and are sold at head shops and on the internet. For example, mephedrone (4-MMC) has been found in 'legal high' products in the UK after it was made a controlled substance in $2010^{5}$ and its use has been linked to several deaths worldwide; ${ }^{6,7}$ therefore development of rapid, economical methods for their detection and quantification is still timely.

A range of chromatographic techniques including High Performance Liquid Chromatography (HPLC) and Gas Chromatography-Mass Spectrometry (GC-MS) have been applied to the detection of synthetic cathinones by many groups, 4, 5, 7-26 however electrochemistry is advantageous as an analytical tool being sensitive, selective as well as low cost and having the potential to be scaled down to a portable device. ${ }^{27-33}$ Previous work ${ }^{2,33}$ has reported novel electroanalytical sensing protocols developed towards the electrochemical oxidation $^{33}$ and reduction of synthetic cathinones, mephedrone and 4'-methyl- $N$ ethylcathinone (4-MEC) using disposable carbon based screen-printed sensors which was successfully applied to their quantification in seized street samples; the protocol was also validated by independently performed HPLC. ${ }^{2}$

In this communication, electrochemical sensors based upon a British 1 pence coin are utilised to successfully detect 4-MMC and 4-MEC for the first time. This novel electrochemical sensing platform based upon British coinage offers an economical approach to the sensing of NPSs 4-MMC and 4-MEC (see Scheme 1) using a 1 pence coin, where the benefits of a sensor costing 1 pence (each side of the coin is useable) are unmistakeable. This new electrochemical approach is explored in ideal solutions and validated towards a seized street sample that has been independently analysed using HPLC. 


\section{Experimental}

All chemicals used were of analytical grade and used as received without any further purification from Sigma-Aldrich (Gillingham, UK). All solutions were prepared with deionised water of resistively no-less than $18.2 \Omega \mathrm{cm}$. All solutions (unless stated otherwise) were vigorously degassed with nitrogen to remove oxygen prior to analysis. The synthetic cathinone hydrochloride (or hydrobromide) salts, were prepared at the University of Strathclyde prior to the legislative change on $16^{\text {th }}$ April 2010 using the methods reported in previous work. ${ }^{33} \mathrm{~A}$ street sample was obtained via internet vendors.

Voltammetric measurements were carried out using a Palmsens (Palm Instruments BV, The Netherlands) potentiostat/galvanostat and controlled by PSTrace version 4.4 . A 1 pence British coin was used as the working electrode along with a platinum wire counter electrode and a Saturated Calomel Electrode (SCE) reference (Radiometer, Copenhagen, Denmark) completing the conventional three electrode electrochemical system. The 1 pence coin has a different composition depending on the time it was minted; between its inception in1971 and September 1992 minted coins comprised of bronze (97\% copper, 2.5 zinc, 0.5\% tin) however post 1992 they have been copper-plated steel. The study herein used coins minted post 1992 in light of the scarcity of coins minted pre-1992. The working electrodes, 1 pence coins, were placed in to a polytetrafluoroethylene (PTFE) 'housing' unit which comprised of a PTFE cap (with $3.0 \mathrm{~mm}$ diameter bore hole leaving a working electrode area of $7.1 \mathrm{~mm}$ ) and PTFE body allowing easy electrical wiring of the coin; see Figure 1 for a schematic representation of the bespoke electrochemical cell. This cell is required to ensure that a reproducible geometric electrode area is obtained. Prior to analysis the 1 pence coin was sonicated in methanol to provide thorough surface cleaning for 2 mins. A new 1 pence coin was utilised for each experiment with each side utilised. Scanning electron microscope (SEM) images and surface element analysis were obtained with a Zeiss Supra 40vp model equipped with an energydispersive X-ray microanalysis package (GenesisEdax). 


\section{Results and Discussion}

The cyclic voltammetric behaviour of 4-MMC using the 1 pence coin (1p-sensor) in aqueous buffer solutions was first explored. Figure 2A depicts the voltammetric response obtained in a solution of $\mathrm{pH} 8.5$ acetate buffer using a 1p-sensor in the absence and presence of 4-MMC. Inspection of the resultant cyclic voltammograms reveals two reduction peaks observed at approximately $-0.4 \mathrm{~V}$ and $-0.6 \mathrm{~V}$ respectively in order of potential cycling and a single oxidation peak at $-0.01 \mathrm{~V}$, all of which are in agreement with the literature regarding the electrochemical behaviour of copper oxide. ${ }^{34}$ Note: the oxidation peak at $-0.01 \mathrm{~V}$ is visible in the absence of 4-MMC and is seen to decrease in intensity upon its addition, this can be attributed to the 4-MMC adhering to the surface of the electrode and obstructing its electroactivity; as such the sensing of 4-MMC is an indirect approach.

The electroanalytical method was explored through additions of 4-MMC into a $\mathrm{pH} 8.5$ acetate buffer using the $1 \mathrm{p}$-sensor; $\mathrm{pH} 8.5$ was chosen since this maintains copper in the form of an oxide $\left(\mathrm{CuO}\right.$ or $\left.\mathrm{Cu}_{2} \mathrm{O}\right)$ which appears useful to provide an indirect sensing platform and is also a $\mathrm{pH}$ that ensures that the degradation of the NPSs, which occurs at alkaline $\mathrm{pH}$ is not significant. As is represented in Figure 3, the oxidation peak observed at approximately -0.01 $\mathrm{V}$ decreases in magnitude upon the addition of 4-MMC. The corresponding calibration plot (Figure 3 Inset) demonstrates the linear response observed $\left(\mathrm{I} / \mu \mathrm{A}=0.1 \times 10^{-3} \mathrm{~A}\left[\mu \mathrm{g} \mathrm{mL}^{-1}\right]+4\right.$ $\left.\times 10^{-5} \mathrm{~A}, R^{2}=0.97, N=3\right)$ over the analytical range studied $\left(1 \times 10^{-3}-0.1 \mu \mathrm{g} \mathrm{mL}^{-1}\right)$. The limit of detection $(3 \sigma)$ for $4-\mathrm{MMC}$ utilising the 1 pence sensor was estimated to correspond to 0.56 $\mu \mathrm{g} \mathrm{mL}^{-1}$ which is a large improvement on our earlier work ${ }^{2}$ which reported a value of $11.80 \mu \mathrm{g}$ $\mathrm{mL}^{-1}$. Note that this novel proof-of-concept has a substantial error when the average of three different coins is used. .

Attention was now turned to another novel psychoactive substance (similar to 4-MMC), 4-MEC (also found in seized street samples ${ }^{2}$ ) wherein the cyclic voltammetric behaviour towards a 1 pence sensor in $\mathrm{pH} 8.5$ acetate buffer is visible in Figure 2B. A similar response to $4-\mathrm{MMC}$ is observed with again a single oxidation peak at $-0.01 \mathrm{~V}$ and the two reduction peaks at approximately -0.3 and $-0.6 \mathrm{~V}$ with the intensity of the oxidation peak again decreasing proportionally to the increasing concentration of 4-MEC. The resultant calibration plot demonstrated a linear response $\left(\mathrm{I} / \mu \mathrm{A}=0.2 \times 10^{-3} \mathrm{~A}\left[\mu \mathrm{g} \mathrm{mL}^{-1}\right]+6 \times 10^{-5} \mathrm{~A}, R^{2}=0.97, N=3\right)$ over the studied analytical range $\left(1 \times 10^{-3}-0.1 \mu \mathrm{g} \mathrm{mL}^{-1}\right)$.with a limit of detection $(3 \sigma)$ equal to $0.50 \mu \mathrm{g} \mathrm{mL}^{-1}$. The electrochemical mechanism is an indirect approach where the 
electrochemistry of copper oxide is inhibited due to the adsorption of the NPSs under investigation. As shown in ESI figures 1 and 2, Scanning Electron Microscopy-Energy Dispersive X-ray microanalysis (SEM-EDX) shows a higher percentage of copper (and therefore $\mathrm{CuO}$ ) in the 1 pence coins minted post-1992. Since the underlying mechanism is dependent upon the presence of copper oxide, post-1992 are ideal. This is fortunate given the scarcity of coins minted pre-1992 further justifying the use of post-1992, which are in current circulation.

To define the qualities of a $1 \mathrm{p}$-sensor, the analytical protocol was applied to a seized street sample (NRG-2), previously analysed, ${ }^{33}$ to determine if the $1 \mathrm{p}$-sensor has merit as a potential sensor for the content of 4-MMC within. Note: Previous analysis ${ }^{2}$ of NRG-2 seized street samples via HPLC (see ESI) has shown their contents comprise of adulterants such as caffeine and benzocaine. ${ }^{2}$ Seized street sample for analysis in this manuscript was known to contain $11.15 \%(\mathrm{w} / \mathrm{w})$ 4-MMC and $87.99 \%(\mathrm{w} / \mathrm{w})$ caffeine (see reference 2 for more details). The standard addition method was utilised in an attempt to quantify the amount of 4-MMC in a street sample and was compared to the previously reported values obtained by cyclic voltammetry (with a carbon screen-printed sensor) and HPLC (See ESI for further details). ${ }^{33}$ Following analysis, the standard addition plot revealed a reported 4-MMC content of $10.99 \%$ $(\mathrm{w} / \mathrm{w})$ which is in excellent agreement with $11.15 \%(\mathrm{w} / \mathrm{w})$ obtained via HPLC and $11.32 \%$ $(\mathrm{w} / \mathrm{w})$ reported previously ${ }^{2}$ using the carbon based screen-printed sensor and is indicative that an electrochemical sensor using British coinage has analytical merit. 


\section{Conclusions}

Proof-of-concept has been shown for the detection of NPSs using a 1 pence coin as a novel electrochemical sensor. This novel approach is extremely cost effective with the sensor costing just 1 pence (both sides of the coin can be used), and a PTFE 'housing' unit which is readily made using cheap components readily available in university workshops. The proposed protocol has been successfully validated against independently performed HPLC in seized street samples. Future work will expand the concept of using British coinage towards other NPSs or using other coinage such as foreign currency. 


\section{References}

1. L. A. Johnson, R. L. Johnson and R.-B. Portier, The Journal of Emergency Medicine, 2013, 44, 1108-1115.

2. J. P. Smith, J. P. Metters, O. I. G. Khreit, O. B. Sutcliffe and C. E. Banks, Anal. Chem., 2014, 86, 9985-9992.

3. G. De Paoli, S. D. Brandt and D. J. Pounder, British Medical Journal, 2011, 342.

4. O. I. G. Khreit, C. Irving, E. Schmidt, J. A. Parkinson, N. Nic Daeid and O. B. Sutcliffe, J. Pharm. Biomed. Anal., 2012, 61, 122-135.

5. S. D. Brandt, H. R. Sumnall, F. Measham and J. Cole, Drug Testing and Analysis, 2010, 2, 377-382.

6. F. Schifano, J. Corkery and A. H. Ghodse, Journal of Clinical Psychopharmacology, 2012, 32, 710-714.

7. H. Torrance and G. Cooper, Forensic Science International, 2010, 202, E62-E63.

8. J. Beyer, F. T. Peters, T. Kraemer and H. H. Maurer, J. Mass Spectrom., 2007, 42, 150160.

9. $\quad$ E. Y. Santali, A. K. Cadogan, N. N. Daeid, K. A. Savage and O. B. Sutcliffe, J. Pharm. Biomed. Anal., 2011, 56, 246-255.

10. P. M. O'Byrne, P. V. Kavanagh, S. M. McNamara and S. M. Stokes, J. Anal. Toxicol., 2013, 37, 64-73.

11. M. J. Swortwood, D. M. Boland and A. P. DeCaprio, Analytical and Bioanalytical Chemistry, 2013, 405, 1383-1397.

12. A. Ambrosi, S. Y. Chee, B. Khezri, R. D. Webster, Z. Sofer and M. Pumera, Angewandte Chemie International Edition, 2012, 51, 500-503.

13. B. D. Paul and K. A. Cole, J. Anal. Toxicol., 2001, 25, 525-530.

14. S. D. Brandt, S. Freeman, H. R. Sumnall, F. Measham and J. Cole, Drug Testing and Analysis, 2011, 3, 569-575.

15. C. Bell, C. George, A. T. Kicman and A. Traynor, Drug Testing and Analysis, 2011, 3, 496-504.

16. P. Jankovics, A. Varadi, L. Tolgyesi, S. Lohner, J. Nemeth-Palotas and H. KoszegiSzalai, Forensic Science International, 2011, 210, 213-220.

17. L. K. Sorensen, J. Chromatogr. B, 2011, 879, 727-736.

18. S. V. R. C.Rambabu, G.Ramu, A.Biksham Babu, Rasayan J. Chem., 2010, 3, 796-799.

19. G. Frison, M. Gregio, L. Zamengo, F. Zancanaro, S. Frasson and R. Sciarrone, Rapid Commun. Mass Spectrom., 2011, 25, 387-390.

20. Y. Al-Saffar, N. N. Stephanson and O. Beck, J. Chromatogr. B, 2013, 930, 112-120.

21. A. J. Pedersen, P. W. Dalsgaard, A. J. Rode, B. S. Rasmussen, I. B. Muller, S. S. Johansen and K. Linnet, Journal of Separation Science, 2013, 36, 2081-2089.

22. E. M. Mwenesongole, L. Gautam, S. W. Hall, J. W. Waterhouse and M. D. Cole, Anal. Methods, 2013, 5, 3248-3254.

23. D. Ammann, J. M. McLaren, D. Gerostamoulos and J. Beyer, J. Anal. Toxicol., 2012, 36, 381-389.

24. S. Strano-Rossi, L. Anzillotti, E. Castrignano, F. S. Romolo and M. Chiarotti, Journal of Chromatography A, 2012, 1258, 37-42.

25. M. Mayer, A. Benko, A. Huszar, K. Sipos, A. Lajtai, A. Lakatos and Z. Porpaczy, Journal of chromatographic science, 2013, 51, 861-866.

26. N. Nic Daeid, K. A. Savage, D. Ramsay, C. Holland and O. B. Sutcliffe, Science \& justice : journal of the Forensic Science Society, 2013, 54, 22-31. 
27. J. P. Metters, R. O. Kadara and C. E. Banks, Analyst, 2011, 136, 1067-1076.

28. J. P. Metters, F. Tan and C. E. Banks, Journal of Solid State Electrochemistry, 2013, 17, 1553-1562.

29. J. P. Metters, M. Gomez-Mingot, J. Iniesta, R. O. Kadara and C. E. Banks, Sensors and Actuators B: Chemical, 2013, 177, 1043-1052.

30. A. V. Kolliopoulos, J. P. Metters and C. E. Banks, Anal. Methods, 2013, 5, 851-856.

31. O. Ramdani, J. P. Metters, L. C. S. Figueiredo, O. Fatibello and C. E. Banks, Analyst, 2013, 138, 1053-1059.

32. J. P. Smith, J. P. Metters, D. K. Kampouris, C. Lledo-Fernandez, O. B. Sutcliffe and C. E. Banks, Analyst, 2013, 138, 6185-6191.

33. J. P. Smith, J. P. Metters, C. Irving, O. B. Sutcliffe and C. E. Banks, Analyst, 2014, 139, 389-400.

34. A. Paracchino, V. Laporte, K. Sivula, M. Grätzel and E. Thimsen, Nat Mater, 2011, 10, 456-461. 
Scheme 1. Chemical structures of A: mephedrone (4-MMC) and B: 4'-methyl- $N$ ethylcathinone (4-MEC)

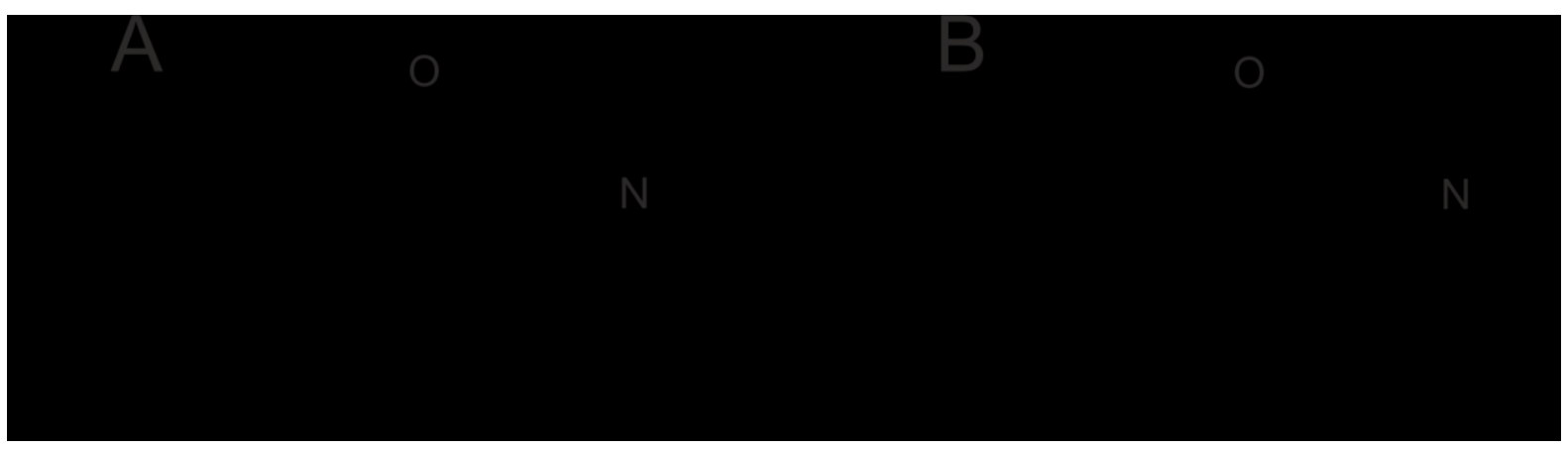


Figure 1 A: Schematic diagram of the Regal Electrochemistry experimental cell PFCE 'housing' unit used to hold the 1 pence sensor in place for analysis and accurately defines the working electrode area. B: Cross sectional diagram of assembled PFCE 'housing' unit with a retrofitted $1 \mathrm{p}$-sensor in place which is then inserted into the solution under investigation.

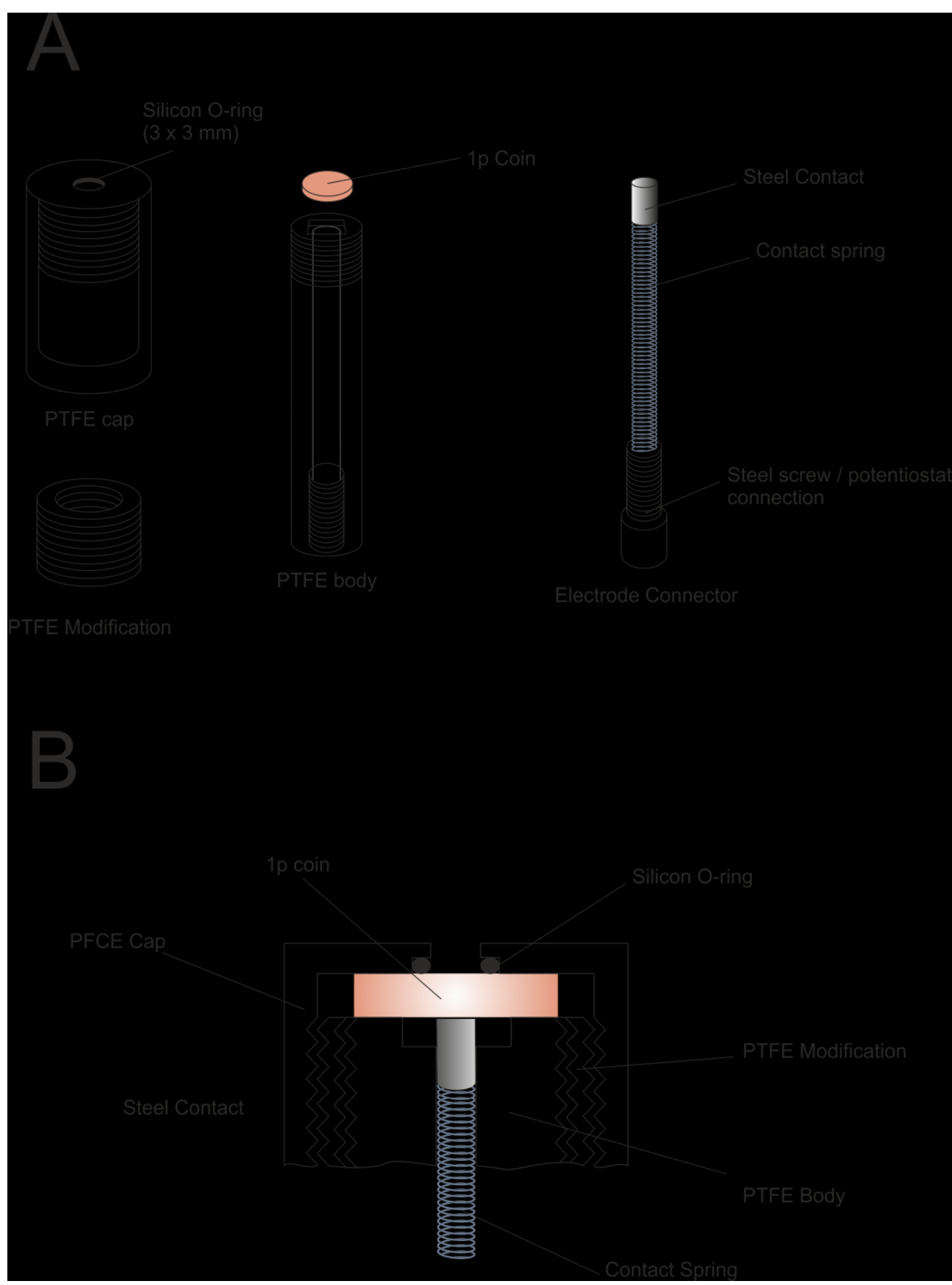


Figure 2. Typical cyclic voltammograms using a 1 pence electrochemical sensor in the absence (black) and presence of 4-MMC (red) and 4-MEC (blue) in pH 8.5 acetate buffer. Scan rate: $50 \mathrm{mVs}^{-1}$ (vs. SCE).

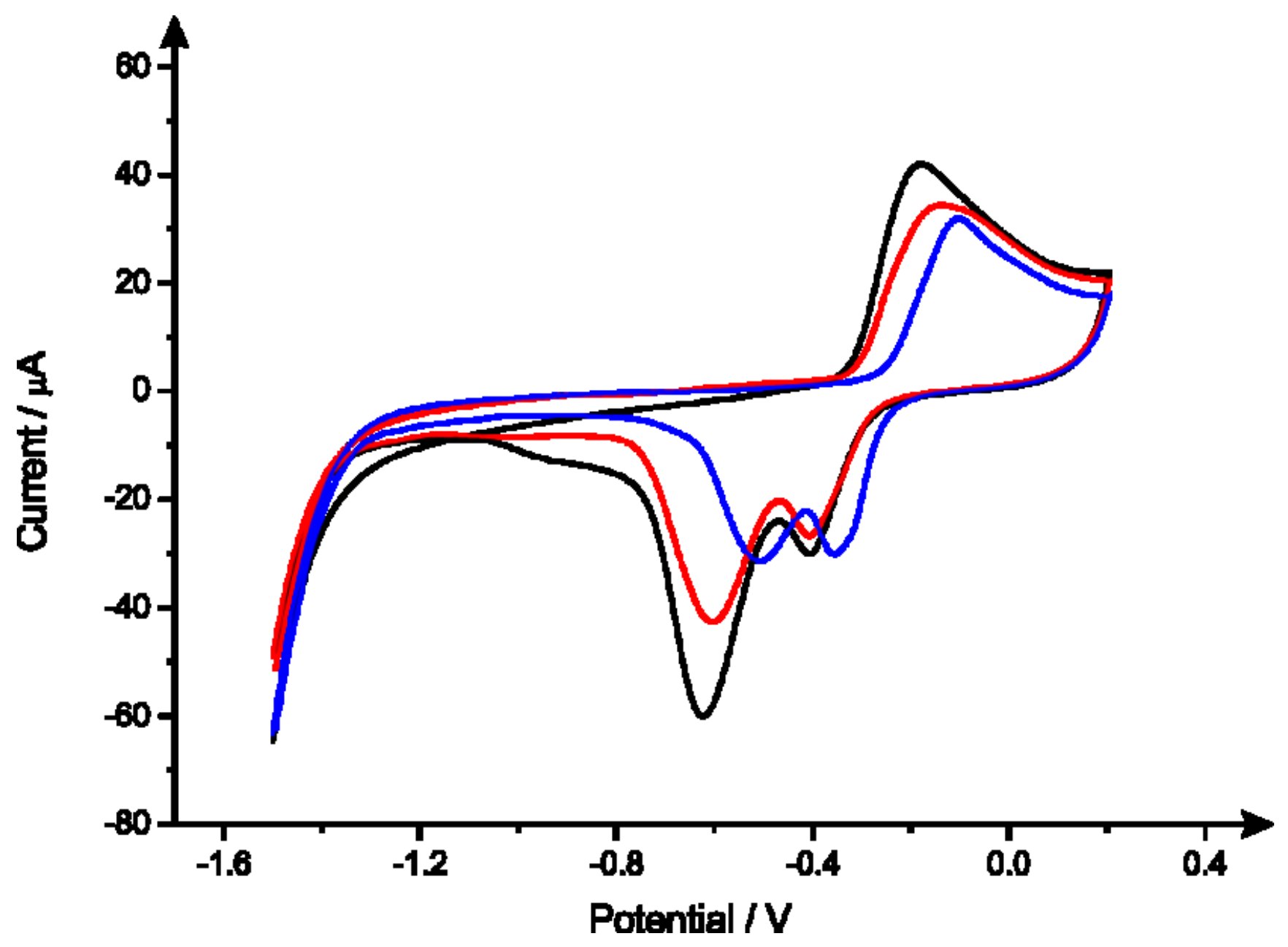


Figure 3. A: Typical voltammetric responses between the range -0.5 and $+0.1 \mathrm{~V}$ as a result of increasing concentrations of 4-MMC using the $1 \mathrm{p}$-sensor recorded in a $\mathrm{pH} 8.5$ acetate buffer. Scan rate $50 \mathrm{mV} \mathrm{s}^{-1}$ (vs. SCE), using the oxidative peak at approximately - $0.1 \mathrm{~V}$ as the analytical peak. Inset: Typical voltammetric responses as a result of increasing concentrations of 4-MMC B: Typical calibration resulting from the analysis of voltammetric signatures obtained in the form of a plot of peak height (current) against 4-MMC concentration using a $1 \mathrm{p}$-sensor in a $\mathrm{pH} 8.5$ acetate buffer over a linear range of $0.00-0.10 \mu \mathrm{g} \mathrm{mL} \mathrm{m}^{-1}$. Scan rate: 50 $\mathrm{mV} \mathrm{s}^{-1}$ (vs. SCE) $(N=3$ - average and standard deviation is plotted).

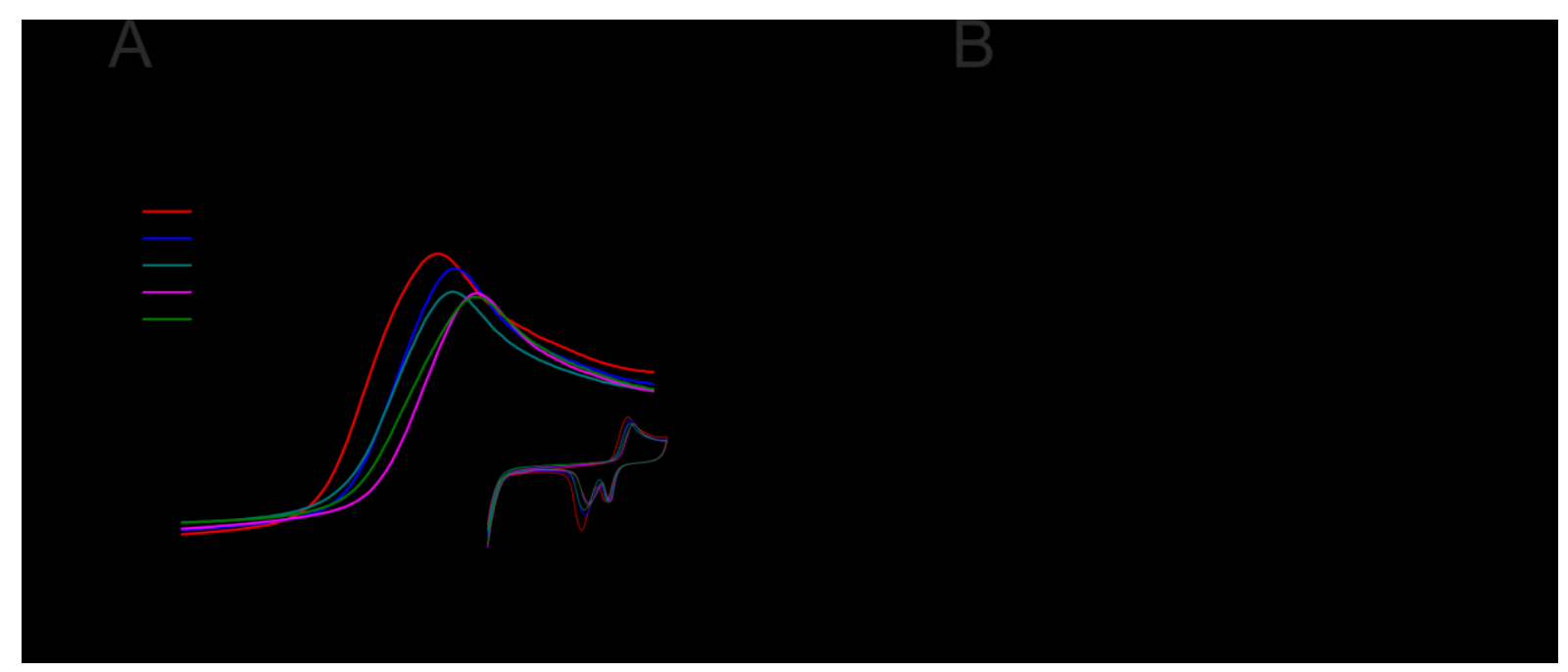




\section{Electronic Supporting Information (ESI)}

High Performance Liquid Chromatography (HPLC) performed on the seized street samples, below is a summary of how this was performed (see reference 2 for more information):

Reverse phase high-performance liquid chromatography was performed with an integrated Agilent HP Series 1100 Liquid Chromatograph (Agilent Technologies, Wokingham, UK) fitted with an in-line degasser, 100-place autoinjector and single channel, tunable UV absorbance detector $(264 \mathrm{~nm})$. Data analysis was carried out using ChemStation for LC (Ver. 10.02) software (Agilent Technologies, Wokingham, UK). The HPLC system was run in binary gradient mode. Solvent A was aqueous ammonium formate buffer $(10 \mathrm{mM}, \mathrm{pH} 3.5 \pm 0.02)$ and solvent $\mathrm{B}$ was methanol; the flow rate was $0.8 \mathrm{~mL}$ min-1 with an injection volume of $10 \mu \mathrm{L}$. Six replicate injections of each calibration standard were performed. The stationary phase (ACE $3 \mathrm{C} 18,150 \mathrm{~mm} \times 4.6 \mathrm{~mm}$ i.d., particle size: $3 \mu \mathrm{m}$ ) used in the study was obtained from HiChrom Limited (Reading, UK). The column was fitted with a guard cartridge (ACE 3 C18) and maintained at an isothermal temperature of $22{ }^{\circ} \mathrm{C}$ with an Agilent S3 HP Series 1100 column oven with a programmable controller (Agilent Technologies, Wokingham, UK). The gradient programme was as follows: $30 \% \mathrm{~B}(0 \mathrm{~min})$ to $60 \% \mathrm{~B}$ at $7 \mathrm{~min}$ to $60 \% \mathrm{~B}$ at $12 \mathrm{~min}$ to $30 \% \mathrm{~B}$ at $18 \mathrm{~min}$.

Preparation of aqueous ammonium formate buffer (10 mM, pH $3.5 \pm 0.02): 1.30 \mathrm{~g}$

Ammonium formate was dissolved in $1.8 \mathrm{~L}$ ultra-pure deionised water and the $\mathrm{pH}$ of the solution adjusted by dropwise addition of formic acid (98-100\%) to $\mathrm{pH} 3.5( \pm 0.02)$. The mixture was transferred to a $2 \mathrm{~L}$ clear glass volumetric flask and diluted to volume with ultrapure deionised water. Prior to use, all mobile phases were vacuum filtered through a 0.45 $\mathrm{mm}$ pore filter paper and degassed for $10 \mathrm{~min}$ at $25^{\circ} \mathrm{C}$ using an ultrasonic bath.

Calibration standards (4-MMC, 4-MEC, caffeine and benzocaine):

$2.0 \mathrm{mg}$ of each component were weighed accurately into $100.0 \mathrm{~mL}$ clear glass volumetric flasks and diluted to volume with mobile phase to give solutions containing all components at 20.0 $\mu \mathrm{g} \mathrm{mL}-1$. This solution was then further diluted with mobile phase to give calibration standards containing $10.0 \mu \mathrm{g} \mathrm{mL}^{-1}, 5.0 \mu \mathrm{g} \mathrm{mL}^{-1}, 2.5 \mu \mathrm{g} \mathrm{mL}^{-1}, 1 \mu \mathrm{g} \mathrm{mL}^{-1}$ and $0.5 \mu \mathrm{g} \mathrm{L}{ }^{-1}$ of each analyte. 
Test solutions: Samples of NRG-2 were obtained from four independent Internet vendors as white crystalline powders in clear zip-lock bags. $10.0 \mathrm{mg}$ of each substance was weighed (in triplicate) accurately into a $100.0 \mathrm{~mL}$ clear glass volumetric flask and diluted to volume with mobile phase. This solution was then further diluted (1:10) with mobile phase to give the test solution. 
Electronic Supporting Information:

ESI Figure 1 - SEM of a A: British 1 pence coin minted pre-1992 and B: British 1 pence coin minted post-1992.

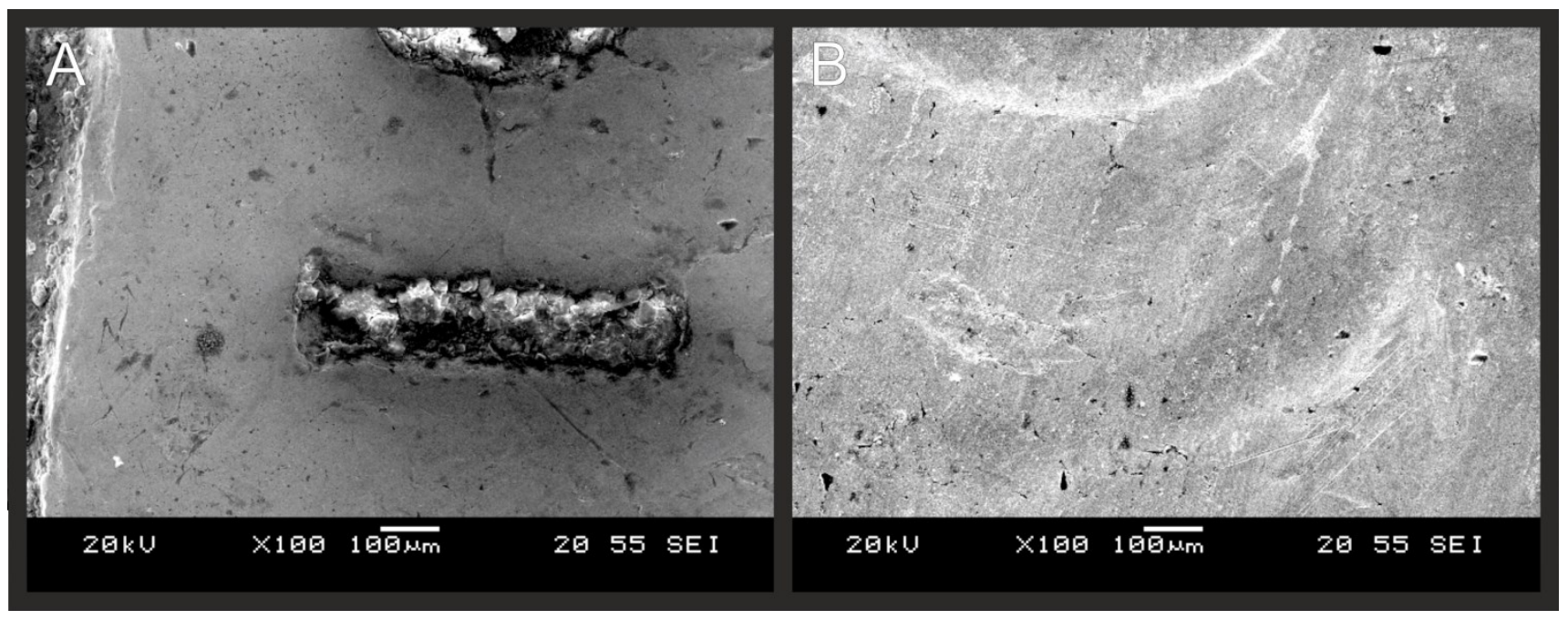


ESI Figure 2 - EDX spectra obtained from a pre-1992 (red) and post-1992 (black) British 1 pence coin following analysis; mean \% composition is listed in the table below.

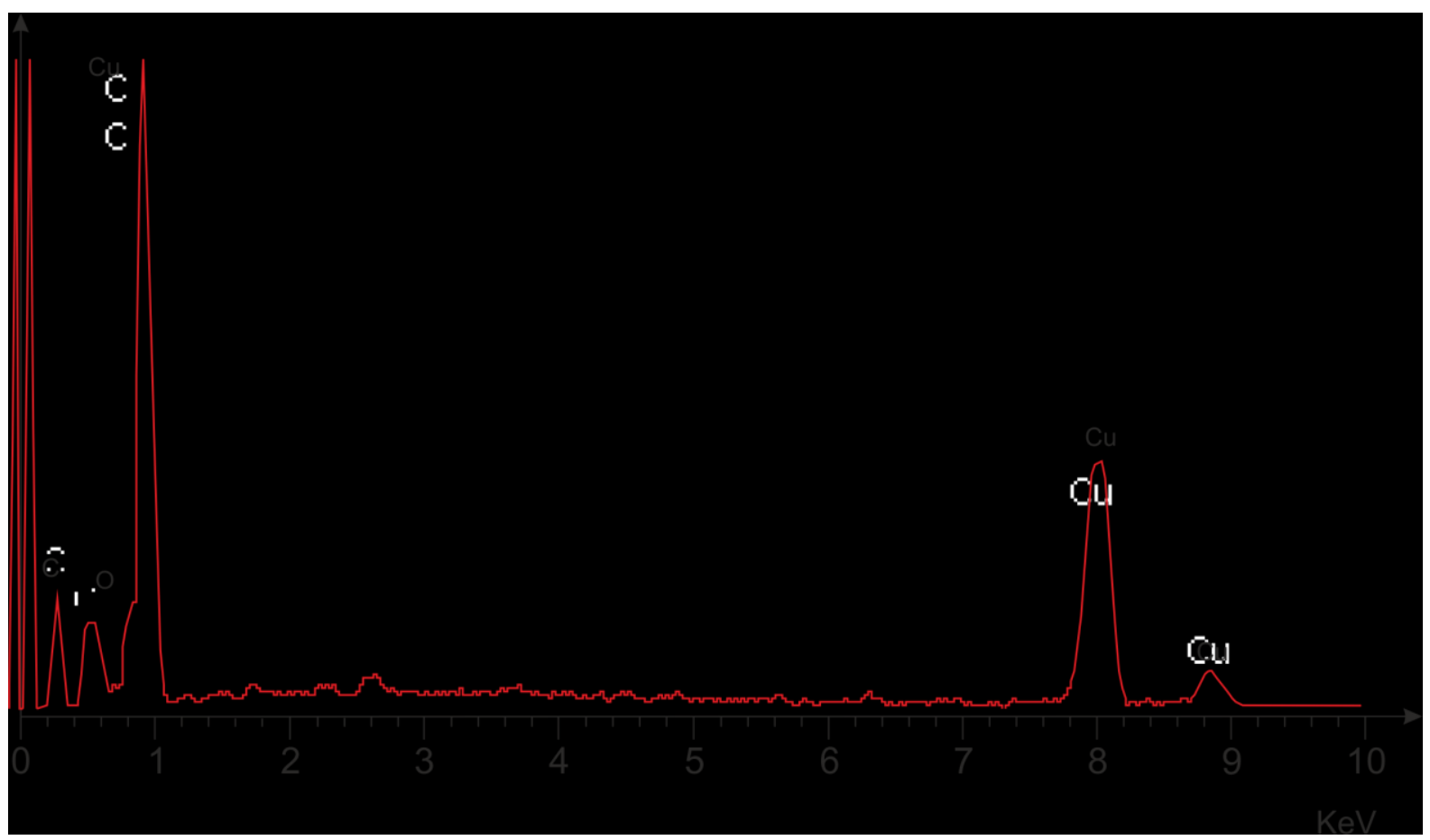

\begin{tabular}{|c|c|c|c|c|c|}
\hline \multicolumn{3}{|c|}{ Pre-1992 } & \multicolumn{3}{|c|}{ Post-1992 } \\
\hline Element & Weight $\%$ & Atomic $\%$ & Element & Weight $\%$ & Atomic $\%$ \\
\hline $\mathrm{C}$ & 26.97 & 57.53 & $\mathrm{C}$ & 7.36 & 28.13 \\
\hline $\mathrm{O}$ & 10.69 & 17.13 & $\mathrm{O}$ & 1.92 & 5.54 \\
\hline $\mathbf{C u}$ & 61.71 & 24.89 & $\mathrm{Cu}$ & 90.72 & 66.33 \\
\hline $\mathrm{Cl}$ & 0.93 & 0.68 & & & \\
\hline Total & 100.31 & 100.23 & Total & 100.00 & 100.00 \\
\hline
\end{tabular}

